\title{
Study on the Living Environment of the Elderly
}

\author{
Dan Zhang \\ College of Arts \\ University of Science \& Technology \\ Qingdao, China \\ qdzhangdan@163.com
}

\begin{abstract}
In this paper, a new topic of elderly support environment with the new design concept is introduced. The research on the living environment of elderly is based on slow city design. The different design concepts and theory for elderly are studied. With the development status and trends of Chinese aging population, the need for elderly living environment design is more and more popular. The slow city life can bring the aged a certain degree of adaptability, comfortability, nature, and health; therefore, it will improve the quality of life of the elderly and will help build a harmonious aging society. The result of the living environment of the elderly that the slow city concept for the elderly living is presented. It is clear that the design of the elderly environment design should be combined with the traditional culture and habit. The conclusion is provided that the design for living environment of the elderly with slow city concept is feasible.
\end{abstract}

Keywords-slow city; aging populations; elderly support environment; natural ecology; landscape design

\section{INTRODUCTION}

Key figures of the sixth national census of China released by the National Bureau of Statistics indicate that up to 0:00 on November 1st, 2010, China's total population is 1.34 billion, while the aged population over 60 accounts for $13.26 \%$.

According to the traditional standards of the United Nations, a nation where elderly population over the age of 60 is more than $10 \%$ can be regarded as an "aging society" ; and more than $14 \%$ is an "aged society". This means that in the next one to two years, China will officially enter the "aging society". As the process of aging in China will continue to accelerate, for the next two decades China will face the pressure of an aging population, and will be ushered in the first population aging shock wave in the "12th Five-Year" period.

The aging process has brought about great challenges to China's economic and social development : on one hand, the burden of the future labor force will increase substantially; on the other hand, as the elderly support institutions, elderly hospitals, and elderly residential care service system are imperfect, the whole society will face a direct trial.

To Develop the elderly facilities to meet the needs of the elderly has become an important part of the strategy and countermeasures addressing problems caused by the aging population.

\section{ELDERLY ENVIRONMENT DESIGN IN CHINA}

\section{A. Importance of Elderly Environment Design}

In nearly half a century, the proportion of the needs of the elderly in the total social demand will be greatly expanded. The elderly support problem is a very important aspect in the elder life. Slow motion "was originally designed by a few hobbies Food the idea, but now it has caused more extensive discussions of culture[1].

This idea in spreading worldwide make people gradually recognize that the original, do so many benefits to more humane, more peaceful way.

So, some of the "slow life" movement of every hue will be popular. Today, its content has been extended to food, work, travel, sports (yoga, Tai Chi, sex), medicine (herbal, homeopathic), education still to urban design, Everything is contained [2].

The quality of their later life is also closely related with the quality and comfort ability of the elderly support environmental. Compared with foreign countries, the elderly support environment in China considerably lags behind; there is big room for improvement in the quality of elderly residential facilities and the environment. The elderly support environment invested and constructed by western developed countries features complete facilities, high quality materials, good construction quality and a full set of services[3]. On the contrary, deficits prevail in the quality, design and the specific service environment of the existing elderly support environment in China and there is large room for changes and improvement. Only by effectively solving the elderly support problems can we promote the substantive development of the industry for the elderly in China.

\section{B. Development of Chinese Elderly Services}

Learning from foreign experience, to develop and construct a high-quality elderly support environment in China, to create a favorable living environment for the elderly, to continuously improve their living conditions, and to offer them a happy old-age life are the most practical measures for us to solve the problems in the aging of the population and to develop the industry for the elderly services. Therefore, construction and development of the elderly support environment is of great practical value and theoretical significance in promoting the development of Chinese industry for elderly services[4]. 


\section{Slow City Movement}

\section{A. Urbanization and Slow City}

Nowadays, urbanization becomes faster and faster, increasing the density of the city. The city is surrounded by more and more industrial facilities and high buildings.Noises replace the quiet living environment, while air pollution has broken the balance of the ecological environment. The city' $\mathrm{s}$ development has increasingly narrowed the space for people's activities. High-speed and high-pressure city life makes people feel exhausted; many people begin to yearn for a pastoral life and to pursue a peaceful and casual life. People come to realize that they should slow down the pace of life, and should do things in a more humane and peaceful way[5].

Slow City is a movement founded in Italy in October 1999. The inspiration of Slow City was the Slow Food organization. Slow City's goals include improving the quality of life in towns by slowing down its overall pace, especially in a city's use of spaces and the flow of life and traffic through them. Slow City is part of a cultural trend known as the Slow movement[6].

"Slow City" is a new urban model. Different from the fast-paced lifestyle, there is more space for people to walk in, more green areas for people to have leisure, more convenient businesses for people to entertain and enjoy themselves, and more squares for people to keep communication. In addition, the "Slow City" advocates the removal of unsightly billboards, neon signs, city wire, the limitation of the speed of cars, the prohibition of car honking,and the harmonious neighborhood communication, and wishes that people will have more time to take care of their families and their children s education.

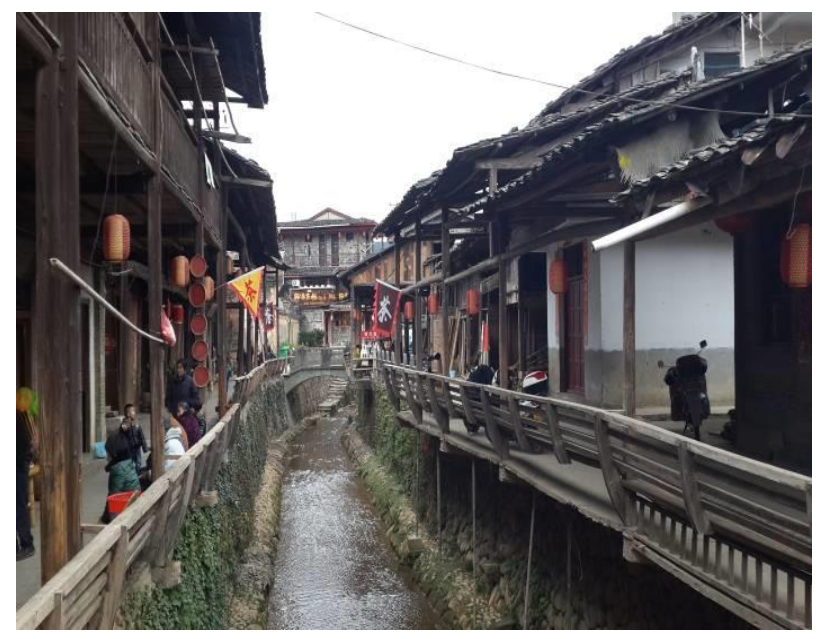

Figure 1. Live in the Slow City

\section{B. Slow City History}

Slow City has expanded broadly beyond Italy. By 2006 national Slow City networks existed in Germany, Norway and the United Kingdom. By mid-2009, fourteen countries had at least one officially accredited Slow City community. In July 2009, the small seaside village of Cowichan Bay in
Canada became the North American continent's first Slow City town.

There are 50 goals and principles that each Slow City town commits to work to achieve. Although there will always be place for improvement these goals serve as tangible benchmarks to improve the quality of life in the city[6].

\section{The main aims of Slow City Movement}

The main aims of the movement are:

Making life better for everyone living in an urban environment.

Improving the quality of life in the cities.

Resisting the homogenization and globalization of towns around the globe.

Protecting the environment.

Promoting cultural diversity and uniqueness of individual cities.

Provide inspiration for a healthier lifestyle.

Additionally, some kinds of "slow living" movement will be popular. Today, its content has been extended to the diet, work, travel, exercise (yoga, tai chi), medicine (herbs, homeopathy), education, and even to urban design, all-encompassing[7].

Study on the problem of international slow city region ecology, traffic, industry, slow life philosophy, cultural protection, to determine the "localization Orient International slow city", specifically from the embodiment: one is "three mountain ecological background, two water, five minutes of cropland" form; two is to " $1+3$ " industrial basis; three is the $\mathrm{Wu}$ Chu culture as the representative of the local culture and environment; the four is the slow way of life to the slow, slow food as the representative of the will ", and the establishment of the sustainable development of Slow City slow City Road, to build domestic standard system, the development trend of international slow City" lead as the ultimate goal, through agriculture and literary activities combination of agriculture and leisure entertainment, the combination of agriculture and health, pension combining interpretation of slow life philosophy, embodies the ecological advantages of Oriental slow city and industry characteristics.

\section{SLOW DESIGN STRATEGY FOR ELDERLY ENVIRONMENT}

\section{A. Elderly Population in China}

More developed regions in China, such as Beijing, Shanghai and other big cities have seen quickly aging populations. The most rich elderly people in the city can not find elderly support institutions suitable for them. In this paper, an innovative elderly support environment in slow city is introduced, and explores the possibility to build a high-end elderly support center integrating such services elderly entertainment, elderly health care, and elderly nursing[8].

After retirement from a busy job, it is time for the elderly to stop and enjoy their life, to enjoy the happiness of family, love, friendship, to enjoy all elements of the nature such as trees, flowers, clouds, streams, waterfalls, and to enjoy the spiritual nutrition drawn from art, traveling, and. reading Slow city life is suitable to a 
certain extent for the Aged, who may relax their body and mind in the nature. The slow city elderly support is a way to materialize slow life.

\section{B. Elderly Support Environment}

In this paper, elderly support environment in slow city is explored from the following sessions:

First, for the elderly, the most important issue is the pleasure of physical health and mood. From a health perspective, the ancient medicine has the motto: "The sun, air, water and exercise are the source of life and health." This sharply points out that the core of the health is close to nature, in harmony with nature[9].

Most Chinese like Tao Yuanming, whose pastoral poems depicted so far are still aspiring. The environmental that is described by his poems is exactly suitable for the elderly. In his masterpieces-- "Peach Blossom Spring", because the nature of the rural scenery so beautiful, people's emotions become calm indifferent, even forgotten time.

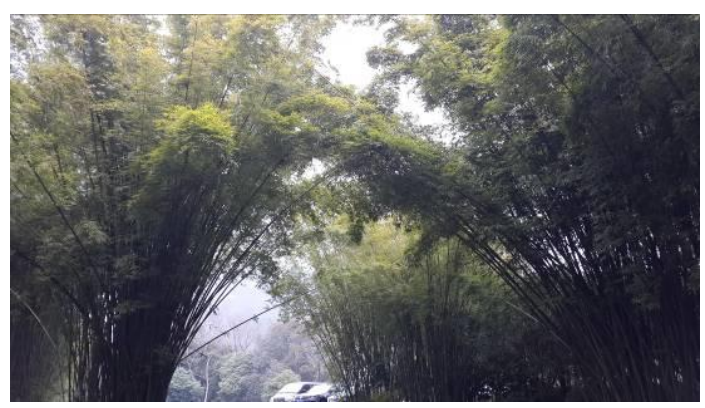

Figure 2. Chinese traditional life environment

\section{USING THE TEMPLATE}

\section{A. Ecological Landscape}

Slow City design for elderly support environmental is around the landscape, the gallery of ecological, cultural, leisure, facilities, chain, landscape axes and other design concepts for the layout. In space design, it is necessary to break through the narrowness of slow city concept, and to integrate the advantageous resources; and it is very important to constantly enrich the connotation of slow city, and highlight the ecological environment of the slow city for elderly support[10].

Secondly, the design should take humanity care as its criteria. As an important part of the international Slow City, the ecological environment should adopt a concept of road different from the traditional one. Subject to the design requirements "less buildings, dense road network, and narrow cross-section " the road design should keep the elderly close to nature, feel natural, and truly enjoy the slow life.

International slow city planning and design should focus on the landscape ecological corridor, ring, cultural area, leisure belt, chain, facilities landscape axis and so on six big design concept, continue to refine, deepen the planning layout.
In the design space, to break through the narrow slow city concept, the integration advantages of resources, and continuously enrich the connotation of slow, further highlight the slow city brand. Two to take humanity as the design criteria.

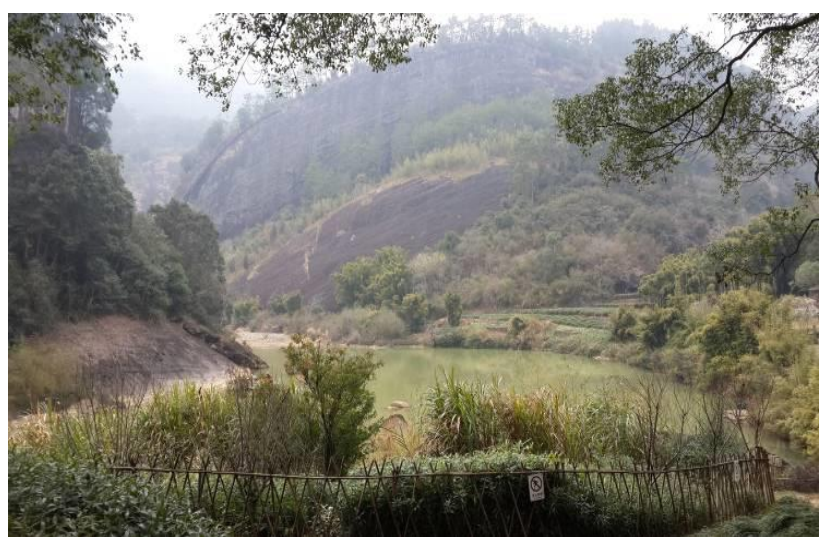

Figure 3. Nature life environment

Thirdly,the design should pay attention to green design. In accordance with the principle of integrate point, line and area, it should continuous deepen the planning concept so as to achieve a state of harmony with the green, shape of mountains, flow of waters, villages, and culture, which will fully demonstrate the features of the slow city's cultural landscape and ecological landscape.With the continuous development of society, fundamentally change the way people travel by sightseeing tours, city tour, leisure travel, steering the village tourism and depth of experience tour[11].

As an important part of international slow city ecological tour, bound to break the traditional concept of roads, design has become an important content of life changing, travel mode, in accordance with the building, federated road network, less narrow section design requirements, do a good job planning and detailed design of transfer system, let tourists, visitors can close to nature, feel natural, fully experience the slow life[12].

The design should focus on green design, according to the combination of point, line, surface principle, constantly deepen the planning conception, form the harmonious state of greening and Yamagata, water potential, village culture, matching, and fully display the international slow city landscape and ecological landscape features.

\section{B. Human engineering of the elderly Landscape Design}

Fourthly, the design should be based on the human engineering of the elderly and the theory of the basic measurement for barrier-free design[13].

In the spirit of "people-oriented, user-friendly design, healthy, comfortable residence", gain a better understanding of the specific requirements of the elderly on the environment, one can create a comfortable living environment for the elderly so as to fully reflects the 
slow city elderly support environment' $\mathrm{s}$ care of the elderly.

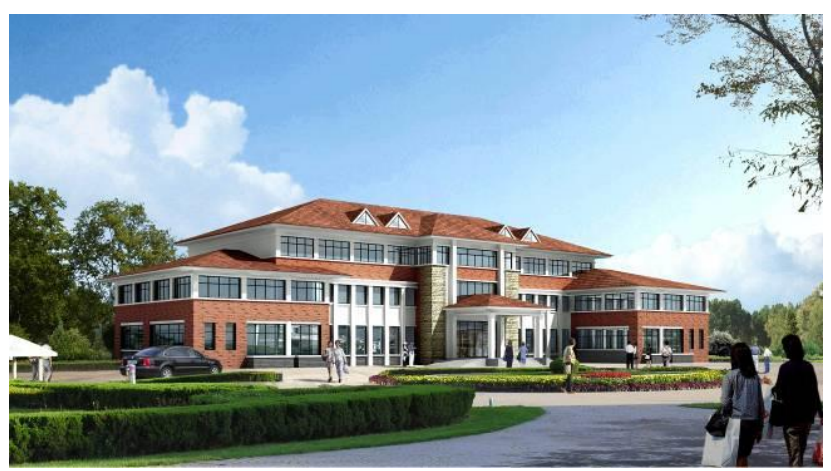

Figure 4. Human engineering of the elderly landscape design

Advocate a slow life style with slow walking and slow eating. Take as its aim " to establish a sustainable development road for slow city, to create a standardized national system for slow city, and lead the development trend of the international Slow City ", taking into consideration the elderly $\mathrm{s}$ preference for planting and cultivation, the design should integrate planting with elderly support and health care as an interpretation of the slow city elderly support, so as to reflect the ecological advantages and features of the Oriental slow city elderly support[14].

\section{Traditional Culture in the Elderly Landscape Design}

Last but not least,to promote traditional culture. The elderly can appreciate the Chinese traditional culture while enjoying the elderly support so as to offer them physical and psychological pleasure and cultivate their taste[15].

When designing, the designers have to consider the rest facilities. In outdoor activities, the elderly should often stop, think, and appreciate the real beauty of the scenery, thus have an emotional exchange with nature.

\section{CONCLUSION}

Undoubtedly in today's increasingly aging problem, to satisfy the inner desire of the elderly, to build elderly entertainment, to build aged care, and to integrate them into one slow city elderly support environment, it can get health, natural living essence, and create harmony aging society, enable the elderly to enjoy their twilight years of life.

\section{ACKNOWLEDGMENT}

This paper is supported by the 2013 Key Culture Project of Shandong Province Department of Culture: Study on the Mobility of Architecture, No: 2014220.
This paper is supported by the 2014 Key Culture Project of Shandong Province Department of Culture: The Study of Residential Environment Based on the Old Aging Society, No:2013373.

This paper is supported by the 2011 Key Culture Project of Shandong Province Department of Culture: Research on Regional Planning City Neighborhood Characteristics, No: 2011176.

This paper is supported by the 2011 Key Culture Project of Qingdao University of Science\&Technology, Study on the Elderly Living Building, No:11xc01.

This paper is supported by the 2011 Key Culture Project of Qingdao University of Science\&Technology, Research on the Design of Public Facilities Based on the Characteristics of Regional Culture, No:10xc32.

\section{REFERENCES}

[1] Mcdonald RI, Kareiva P, Forman RTT, "The implications of current and future urbanization for global protected areas and biodiversity conservation", Biol Conserv Vol. 141, pp. 1695-1703, 2008.

[2] Tian Shan-chuan, "A REVIEW OF FOREIGN STUDIES OF THEORIES AND METHODS ON LIVABLE CITY”, Economic Geography;2008-04

[3] Zhou Yongzhen, “On Further Development of Inner Mongolia Cultural Tourism--Based on an analysis of cultural heritage authenticity" Territory \& Natural Resources Study; 2010-05

[4] Wang Yuncai, Hu Ding, Li Wenmin, "Micro-Ways and MacroEcology Realization-Discussions on the New Mission of Landscape Architecture Development under the Ecology Civilization Proposal", Journal of Chinese Landscape Architecture, pp. 41-45, January 2009(In Chinese).

[5] IMeyer EK, Sustaining beauty, "The performance of appearance: a manifesto in three parts", J Landscape Arch Spring, pp. 6-23, January 2008.

[6] Ostrom E, "Frameworks and theories of environmental change", Glob Environ Change Vol. 18, pp. 249-252, 2008.

[7] Ma Li-li,Wang Jie, " landscape design of corridor color Based on the continuity - landscape planning of corridor color in jiaojiang, Taizhou",Urban Planning,2006(9):94-97.

[8] Sun Peng and Wang Zhi-fang, "landscape design of the urban river and water front followed by the natural process", Urban Planning, 2000 (9): 18-21

[9] WU Yu-yang, "Application of Rosaceae in Spatial Composition of Gardens"[J];Acta Agricultural Jiangxi;2011-02

[10] Huang Wenshan[;A Study on the Connotation of the Modern Science of Landscape Architecture[J];Planners;2004-04

[11] Mayer,T.N.Jackson, and M.E.Lockley,A New Role for Microcontroller Courses:Integrating EE Curricula,Frontiers In Education,25th Annual Conference ,November 1-4,1995.

[12] YE Lin, "The landscape design and thought of the new century garden in the city of Nanjing", Shanxi Architecture ;2008-18

[13] Pink,Sarah, "Urban social movements and small places", City:analysis of urban trends,culture,theory,policy,action,Volume 13,Number 4

[14] Liang Shuyu,'Urban buildings and garden scenery," Shanxi Architecture; 2012-22

[15] Clare Cooper Marcus with Carolyn Francis, "People Places:Design Guidelines for Urban Open Space”, John Wiley\&Sons,2nd Revised Edition 2006 